DOI 10.17150/978-5-7253-3001-4.35

C.К. $\boldsymbol{K A H H}$

УДК 33:94(571)

ББК $65.03(2) 53$

\title{
КОМИТЕТ СИБИРСКОЙ ЖЕЛЕЗНОЙ ДОРОГИ И УСТРОЙСТВО ЧУЙСКОГО КОЛЕСНОГО ПУТИ
}

На примере истории вопроса об устройстве Чуйского колесного пути к китайской границе от селения Онгудай к урочищу Кош-Агач рассматриваются цели Комитета Сибирской железной дороги, особенности и приоритеты его деятельности, а также основные подходы к решению задач освоения Сибири.

Ключевые слова: Транссибирская железнодорожная магистраль, Чуйский тракт, Комитет Сибирской железной дороги (1892-1905), принципы и задачи деятельности.

S.K. KANN

\section{COMMITTEE OF THE SIBERIAN RAILROAD AND THE CONSTRUCTION OF THE CHUYA WHEEL TRACK}

Based on the history of the issue of setting up the Chuya wheel track from the village of Onguday to the Kosh-Agach locality and to the Chinese border, the objectives of the Committee of the Siberian railroad, the features and priorities of its activities, as well as the main approaches to solving problems of developing Siberia are considered.

Keywords: Transsiberian railway, Chuya wheel track, Committee of the Siberian railroad (1892-1905), principles and objectives of activities.

Изучению истории создания Чуйского тракта в Горном Алтае в связи с развитием торговых отношений с Китаем посвящено немало исследований. Об этой легендарной дороге много писали и в дореволюционное, и в советское время, ее продолжают изучать и сейчас [7], но как отдельные сюжеты, так и целые «сквозные» темы, связанные со ста- 
новлением единой транспортной системы и ее влиянием на сибирские регионы и общее развитие страны до сих пор освещены недостаточно [8, с. 105-106; 12, с. 73; 15; 17, с. 276]. Так же отсутствуют и обобщающие труды по истории Чуйского тракта, несмотря на некоторые работы популярного и краеведческо-публицистического характера, появившиеся в последнее время [1; 3; и др.].

В связи с этим, один из недостаточно разработанных сюжетов касается мероприятий Комитета Сибирской железной дороги (КСЖД), последовательно осуществленных в течение 1893-1903 гг. и, фрактически, позволивших преобразовать вьючную тропу, существовавшую с XVIII в., в относительно производительную колесную дорогу, резко увеличившую товарооборот Алтая с северо-западными провинциями Китая. Этот сюжет важен и с точки зрения истории самого КСЖД, так как более глубоко раскрывает цели и механизм осуществления полномочий, принципы централизующей и направляющей деятельности комитета по реализации планов изучения и освоения Сибири.

Предыстория преобразования торгового пути по долине р. Чуи началась задолго до учреждения КСЖД. Слабая провозная способность этой дороги вызывала неоднократные попытки ее улучшения. Примерно половина пути от Бийска до китайской границы (около 240 верст), была еще относительно сносной для проезда, другая же - от селения Онгудая до урочища Кош-Агач (260 в.) - представляла малопроезжую тропу, годную только для караванов вьючных лошадей и верблюдов и прогона скота. Именно скот в больших количествах к началу XX в. стал главным товаром на Чуйском тракте [2, с. 111-112]. Но и гурты, и караваны ожидали огромные трудности. Во множестве мест дорогу пересекали водотоки, непреодолимые в ненастье.

«Описание торгового пути от Онгудая до Кош-Агача» рисует переправы через р. Катунь таким образом:

«Берега Катуни на перевозе Кор-кечу очень высоки, круты и совершенно не приспособлены для подъема и спуска в телеге: к ним с трудом пристают лодки, паром и переплывший скот. Громадное камни сплошного гранита до 1000 пудов весом, нагроможденные по обоим берегам, сильно затрудняют доступ к реке, и самая переправа, при самых примитивных устройствах перевоза, внушает серьезные опасения. Товары и людей перевозят через Катунь в лодках, и только при малой и средней воде иногда пользуются паромом. Лошади и гурты скота следуют через реку вплавь. Их насильно сталкивают в воду и, снесенные быстрым течением, животные с величайшими усилиями пристают в различных местах противоположного берега, часто с избитыми до крови членами о подводные камни. Ширина реки на месте переправы в самую малую воду зимою 35 саж., в остальное же время она меняется и достигает, судя по отметкам берегов, до 70 саж. В самую большую воду переправы 
через Катунь совсем не бывает, так как переезд становится в эту пору очень опасным: вода, поднявшись выше среднего уровня, захватывает в верховьях своих громадные лиственницы, сваленные по берегам ветром, и мчит их с быстротою своего течения: тяжелые деревья несутся большей частью под водой и при ударах о подводные камни неожиданно вырываются на поверхность реки и могут опрокинуть и разбить любой паром, не говоря уже о лодках...

Несколько ниже устья правый берег Катуни скалист и тянется совершенно отвесно, упираясь в воду, до самого бома Куй-таш, и это обстоятельство служит препятствием при переправе лошадей и гуртов скота вплавь, так как случайно снесенное течением животное, не имея возможности пристать к скалистому берегу, неминуемо должно погибнуть. Следовательно, и скот будет в силу необходимости переправляться на пароме, что избавит его от гибели и тех ужасных мучений, невольными свидетелями которых является всякий проезжающий через р. Катунь на перевозе Кор-кечу» [13, л. 44 об.-45, 46 об.-47].

Еще в 1869 г. бывший генерал-губернатор Западной Сибири А.П. Хрущов поднял вопрос об усовершенствовании Чуйского пути, но одновременно он же ходатайствовал о проведении еще одной дороги от Семипалатинска на Кош-Агач по долине Бухтармы. Естественно, что работы по сооружению двух дорог требовали значительных затрат, поэтому в 1874 г. министерство финансов запросило деньги только на одну Семипалатинскую дорогу, как более дешевую. Со временем, однако, выяснилось, что торговцы все-таки предпочитают дорогу по долине р. Чуи и в начале 1877 г. новый генерал-губернатор Н.Г. Казнаков заявил о необходимости обратить Чуйскую дорогу в колесную, а работы по Семипалатинской дороге прекратить. Со своей стороны, отозвалось и министерство иностранных дел, которое отношением № 784 от 17 марта 1877 г. предположило, что новый путь может служить новым исходным пунктом для доставки чая из Китая в Россию. Понятно, что идея перевозки чая через Кобдо не могла обрадовать кяхтинских чаеторговцев, которые десятилетиями возили чай через Калган.

C середины 1880-х гг., т.е. непосредственно перед началом постройки Сибирской железной дороги, Чуйский путь обрел энергичного заступника в лице российского генерального консула в Урге Я.П. Шишмарева (1833-1915). Помимо значения подвозного пути к железнодорожной магистрали дорога от китайской границы вглубь Сибири приобретала важные стратегические функции. В записке от 24 сентября 1884 г. Шишмарев писал, что «соседство обширного многолюдного и поставленного географическим положением в богатые условия Китая, бесспорно должно служить залогом к обоюдному торговому отмену России с ним, к сбыту на его рынках наших мануфактурных и фабричных произведений» $[13$, л. 1]. Тем не менее, несмотря на благоприятные условия и вы- 
годные договоры, открывающие доступ к рынкам Китая, «наша торговля, - заключал Шишмарев, — больше чем неудовлетворительна». Так, в 1883 г. отпуск русского товара снизился вдвое против предыдущего года (с 6,4 млн до 3,9 млн р.). По мнению консула, российские товары в портах приморского Китая не выдерживали конкуренции с европейскими и американскими товарами, поэтому главное направление нашей торговли следовало срочно изменить на северо-западные провинции Китая [13, л. 2 об.].

Если до заключения Пекинского трактата (1860), по словам Шишмарева, торговля с Китаем производилась исключительно через Кяхту, то Пекинский договор «совершил переворот в сухопутной торговле» и Кяхта, где спрос на русские товары падал еще до заключения договора, окончательно «потеряла свое значение как для русских, так и для китайцев». При обмене своих товаров на чай русским купцам часто приходилось приплачивать золотом и серебром. Шишмарев ссылался на брошюру директора Кяхтинской таможни Н.К. Крита, где упоминался невыгодный характер «торгового стремления» в приморский Китай и высказывалось предположение направить русскую торговлю в западные провинции Китая, Кульджу, Чугучак и Кашгар [4].

Впрочем, по словам Шишмарева, главная трудность для русской торговли с внутренним Китаем заключалась в неустроенности приграничного участка Чуйской дороги от селения Онгудая до Кош-Агача. Доставка этим путем громоздких и тяжелых вещей была невозможна. Соответственно и провозная плата была очень дорогой. За перевозку на расстояние 250 верст по вьючной дороге брали от 1,80 р. до 2 р. с 1 пуда груза, тогда как за такое же расстояние по колесному пути между Онгудаем и Бийском платили всего лишь по 20 к. с пуда [13, л. 7].

«Безотлагательное устройство на упомянутом участке колесной дороги, - считал Шишмарев, - требуется нашими интересами, как торговыми, так и другими». Он обратился к состоящему при Министерстве императорского двора инженер-поручику М.А. Брещинскому с просьбой определить затраты по устройству Чуйского пути и после изучения вопроса на месте Брещинский подсчитал необходимую сумму в размере 75000 р. по минимальной смете и 100 тыс. по максимальной. Цена была весьма высокой, так как в смете, помимо указания на необходимость взрывных работ (несколько тысяч кубов), выписку сотен «капсулей», устройство насыпей, гатей, мостов, рубку леса и пр. особо оговаривалось, что дорога проходит по незаселенной местности, поэтому цена на рабочих была взята примерно - с расчетом их подвоза. Предполагалось также иметь до 7000 рабочих из солдат.

Одновременно желание поддержать работы на тракте высказали и «общественные силы» - Бийское городское общество, изъявившее готовность принять на себя надзор и содействие по устройству дороги. 
Общество составило комитет из 10 членов и утвердило соответствующий протокол (постановление Бийской городской думы № 20 от 14 мая 1884 г.) [13, л. 11-13 об.]. Чуть позже подоспело и решение комитета высочайше утвержденного Общества для содействия русской промышленности и торговле, собравшегося поддержать «торговое движение русских произведений» через Сибирь в Китай, для чего принять меры для обустройства сухопутного пути через Бийск и селения Онгудай и Кош-Агач до Кобдо. О получении соответствующей бумаги сообщило МПС в хозяйственный департамент МВД, который, в свою очередь, 8 января 1885 г. с № 145 перенаправил ее к министру фринансов [13, л. 18-19 об.].

Наконец, 18.12.1892 г. новому министру фринансов С.Ю. Витте поступило представление № 4537 от томского губернатора Г.А. Тобизена. В нем, видимо, в предположении скорого проведения Сибирской магистрали, критиковалась Кяхта и старый маршрут доставки товаров, подчеркивалось большое государственное значение Чуйского пути, способного, наряду с водным путем от Бийска до Тюмени и сооружаемой магистралью, резко усилить товарное движение, сделать его круглогодичным, способствовать заселению прилежащих местностей и т.д. [13, л. 40-42 об.].

В таком, собственно, виде вопрос об устройстве Чуйского колесного пути и перешел в ведение недавно учрежденного Комитета Сибирской железной дороги. Налицо присутствовал ряд существенных и непростых обстоятельств. Во-первых, - длительная бюрократизация и затянутость вопроса, когда в его разрешение включились губернаторы и министры, различные ведомства (МВД, МПС, финансов, иностранных дел, военное, императорского двора, кабинета е.и.в.), общественные силы (городские и научно-промышленные общества).

Во-вторых, - полная неопределенность с финансами, т.е., помимо их вечной скудости, присутствовала еще и совершенная неясность, кто, на что и в каком размере будет тратить доступную наличность. Так, например, министр внутренних дел И.Н. Дурново, ссылаясь на то, что в его ведении «состоят дороги, устраиваемые и содержимые лишь для внутренних сообщений в губерниях на счет средств местных земских повинностей», а путь от Онгудая до Кош-Агача предполагает служить «исключительно потребностям внешней торговли» или же военно-стратегическим целям, намекал на то, что и затраты должны нести ведомства или финансов, или военные. Предшественник Витте на посту министра финансов Н.Х. Бунге интересовался, у кабинета е.и.в. не примет ли он участие в обустройстве дороги, взяв на свой счет часть расходов, или, во всяком случае, не согласится ли Алтайский горный округ на безвозмездный отпуск стройматериалов и инструментов.

В-третьих, необходимо было урегулировать вопросы, как теперь говорят, «государственно-частного партнерства», так как бийские купцы были готовы участвовать в деле своими деньгами, но их возможно- 
сти, как справедливо заметил А.В. Старцев, были очень ограничены, и даже при тех высоких прибылях, которыми славилась чуйская торговля, купцы не могли выложить десятки тысяч рублей, не разорив себя [17, с. 278-279; 14, с. 165-166]. Замысел же состоял в том, чтобы предоставить некоторую долю инициативы местному торговому сословию, опираясь на его личный интерес к устройству дороги и одновременной экономии средств.

Ходатайство гофмейстера Тобизена, поддержанное министром финансов С.Ю. Витте, рассматривалось в 10-м заседании КСЖД 10 ноября 1893 г. По уточненной (в сторону уменьшения) смете на переделку вьючной тропы требовалось 48565 р. [13, л. 82 об.] Кабинет е.и.в. давал 3000 р. на материалы и взрывчатые вещества для порохострельных работ, а министерство финансов испрашивало 20500 р. на производство изысканий и еще 45500 р. - на прокладку пути (№ 3333 от 4 ноября 1893 г., по канцелярии МФ). По высочайше утвержденному 18 ноября 1893 г. положению КСЖД к отпуску из фонда вспомогательных предприятий Сибирской железной дороги (ФВП) было разрешено 48 тыс. р., в том числе 2,5 тыс. - на производство изысканий [13, л. 87-87 об.].

По словам управлявшего делами КСЖД А.Н. Куломзина, поначалу комитет отнесся вполне «сочувственно» к обустройству дороги. «Дело получило бы быстрое осуществление, если бы не два обстоятельства: одно - это сделанное в ходе заседания военным министром предложение командировать двух инженерных офицеров из состава Омского округа для окончательного исследования пути и второе - это вскоре состоявшийся перевод Тобизена в Харьковскую губернию. Инженеры рассчитали стоимость дороги в 400 тыс. р., и таким образом, расчет в 45 тыс. р. показался сомнительным, а вновь назначенный в Томск губернатор не внушал того доверия, которым пользовался Тобизен» [5, с. 462]. Дело затянулось, и колесная дорога в общих чертах была сооружена только через десять лет.

Дальнейшее изучение вопроса с участием военных выяснило, что средств, отпущенных из ФВП, совершенно недостаточно. Так, например, технический строительный комитет и департамент шоссейных и водяных сообщений исчислили на эту надобность от 450000 до 560000 р. В результате такого «открытия» в 1893 г. к работам так и не приступили, a 45500 р., предназначенные на устройство пути, были возвращены обратно в ФВП.

В 1896 г. вопрос вновь поднял преемник гофмейстера Тобизена - генерал-лейтенант А.А. Ломачевский, причем предположение об устройстве дороги поддержал и министр земледелия и государственных имуществ, ввиду важности открыть обширный сбыт в Западном Китае для сибирского хлеба и других сельхозпродуктов. На основании произведенного расчета и вследствие изъявленного министерством импера- 
торского двора согласия отпустить на этот предмет 20000 р. и материалы, необходимые для строительства, общая сумма необходимого ассигнования была определена вновь в 45000 р.

В 34-м заседании КСЖД 8 декабря 1899 г. последовало заявление военного министра о том, что при постоянно прогрессирующем развитии края, необходимо принять меры для его обороны, недостижимой без удобных путей сообщения. Во внимание к этому заявлению, а также после лично высказанного Николаем II мнения о важности Чуйского пути, 19 декабря 1899 г. царь утвердил положение КСЖД, согласно которому в распоряжение МВД на улучшение вьючной тропы было ассигновано 45000 р., с соответственным увеличением суммы, занесенной в § 24 сметы расходов ФВП 1900 г. Вместе с тем, присутствовавшие в заседании члены КСЖД согласились, что дальнейшие (после 1900 г.) ассигнования на улучшение вьючной дороги Онгудай - Кош-Агач или переделки ее в колесную, должны быть относимы на общие ресурсы государственного казначейства [6, 1903, т. 25, л. 627].

По предварительно составленной смете общая стоимость необходимых работ определилась в сумме 55 971,07 р. Но изыскания указали на недостаточность и этой суммы - тем более, что было признано соответственным не ограничиваться одним улучшением тропы, а переделать ее в колесную дорогу, удобную для передвижения караванов. Из-за трудностей найма рабочих, в связи с мобилизацией, а также из-за проблем с заготовкой материалов, работы начались только 7 мая 1901 г. Наблюдение за их ходом было поручено Барнаульскому уездному исправнику, а сами работы велись через подрядчика - по проекту, составленному горным инженером И.И. Билем, командированным от главного управления Алтайского округа.

Когда приступили к реконструкции пути, оказалось, что и отпущенных средств, в общей сложности в размере 65000 р. (20 $000+45000$ р.), не хватает, так как дорогу предполагалось удлинить, чтобы избежать устройства двух переправ через Катунь, небезопасных для караванов. Было решено проложить колесный путь хотя бы на одном участке в пределах имевшихся средств. С начала мая до октября 1901 г. на протяжении приблизительно 90 верст была устроена вполне удобная и безопасная дорога от Онгудая до террасы вблизи Ерь-Бома 2. Число задействованных рабочих колебалось от 80 до 158 человек. Подрывные и порохострельные работы выполнялись командой сапер 6-й бригады из двух офицеров и 30 нижних чинов.

Когда очередное ассигнование было истрачено, колесная дорога все еще была обустроена лишь частично. «Томский губернатор князь Вяземский, - пишет Куломзин, - исчислял стоимость остальной части дороги в 55 тыс., из которых 10 тыс. р. жертвовали бийские купцы, заинтересованные в прокладке этого нового торгового тракта в Монголию. Вопрос 
заключался в том, откуда достать остальные 45 тыс. р. «Я, - писал Куломзин, - считал этот тракт скорее общегосударственного значения. Подъездным путем к Сибирской железной дороге по отдаленности его от рельсового пути он не мог быть потому, что отнесение его на смету вспомогательных предприятий, и без того уже возраставшую с каждым годом, я считал несправедливым. Военное ведомство отказалось принять расход этот на свой предельный бюджет, хотя представители Военного министерства находили, что в случае непроведения дороги ведомству этому придется держать большую численность войск в пределах Западной Сибири для защиты нашей монгольской границы. Как бы то ни было, но подготовительная комиссия единогласно признала настоятельным продление дороги, и разногласие ограничилось вопросом об источнике для покрытия расхода. Представители Министерств военного и внутренних дел настаивали на ассигновании необходимых средств за счет сметы вспомогательных предприятий. Остальные члены не находили этого возможным. В таком виде вопрос этот и был внесен в Сибирский комитет. В заседании государь решительно высказался за общегосударственное и притом стратегическое значение Кош-Агачского колесного пути, так что Сергею Юльевичу Витте, представители которого горячо спорили против этой дороги в подготовительной комиссии, ничего не оставалось, как высказаться за принятие испрашиваемых 45 тыс. р. за счет 12 млн фронда. В таком смысле и состоялось высочайшее повеление» [5, с. 878].

Другими словами, С.Ю. Витте, несмотря на все его отговорки о том, что «казначейству предстоят крупные затраты для удовлетворения многих первостепенных нужд государства», что «он не считает возможным ассигновать в текущем году кредит для сказанной потребности и полагал бы отложить окончание работ до более благоприятного времени» [6, 1903, т. 25, л. 624], пришлось согласиться и возложить издержки на общие ресурсы казначейства. По журналу № 71 заседания КСЖД 15 января 1903 г. и при личной настойчивости Николая II утвердили решение «отпустить в распоряжение министра внутренних дел на окончание колесной дороги между селением Онгудай и урочищем Кош-Агач 45000 р. с отнесением сего расхода на счет 12 млн р., предназначенных по действующий Государственной Росписи доходов и расходов на непредусмотренные сметами экстренные в течение года надобности» [6, 1903, т. 25, л. 1089 об.].

Таким образом данный расход не был принят на смету ФВП, исходя из того положения, что его средства предназначены «преимущественно на ведение переселенческого дела», тогда как Чуйская колесная дорога имеет значение общегосударственное, но не переселенческое. Эта история ярко высветила особенности борьбы и согласования интересов разных ведомств в рамках проекта Сибирской железной дороги, которым руководил КСЖД. Ограничивая произвол ведомств, принимая меры 
к поощрению частной инициативы, Комитет достигал поставленных перед ним целей, несмотря на вполне ощутимые организационные и финансовые трудности.

\section{Список использованной литературы и источников}

1. Грехова Е. А. Чуйский тракт до монгольской границы. Историко-краеведческий очерк / Е. А. Грехова. - Бийск, 2006. - 100 с.

2. Зиновьев В. П. Торговый обмен Сибири и Центральной Азии в начале XX в. / В. П. Зиновьев // Сибирь и Центральная Азия: проблемы региональных связей. XVIII-XX вв. - Томск : Изд-во Том. ун-та, 1999. - С. 108-120.

3. Кислицын В. Н. Чуйский тракт. Времена. Имена / В. Н. Кислицын, А. М. Малолетко. - Барнаул : [б. и.], 2013. - 88 с.

4. Крит Н. К. Будущее кяхтинской торговли / Н. К. Крит. - СПб., 1862. - 103 с.

5. Куломзин А. Н. Пережитое. Воспоминания / А. Н. Куломзин ; сост., вступ. ст., коммент. и прим. К. А. Соловьева. - М. : Политическая энциклопедия, 2016. - $1038 \mathrm{c}$.

6. Материалы Комитета Сибирской железной дороги. - СПб. : Гос. тип., 1893-1904. - Т. 1-28.

7. Подрезов М. В. История Чуйского тракта : автореф. дис. ... канд. ист. наук / М. В. Подрезов. - Томск, 2018. - 20 с.

8. Подрезов М. В. История Чуйского тракта: обзор основной литературы / М. В. Подрезов // Вестник Томского государственного университета. - 2017. № 414. - С. 103-107.

9. Пустогачева Т. С. История развития путей сообщения в Горном Алтае в конце XIX - начале XX в. / Т. С. Пустогачева // Известия Алтайского государственного университета. — 2010. — № 4-2 (68). — С. 182-189.

10. Пустогачева Т. С. Источники по изучению истории развития транспорта, путей сообщения и торговли в Горном Алтае во 2-й пол. XIX - 1-й пол. XX в. I Т. С. Пустогачева // Вестник Томского государственного университета. - 2011. № 345 . - C. 88-92.

11. Пустогачева Т. С. Проблемы развития Чуйского тракта в 60-90-е гг. XIX в. / Т. С. Пустогачева // Вестник Томского государственного университета. История. - 2011. — № 1 (13). - С. 41-44.

12. Пустогачева Т. С. Развитие транспорта, путей сообщения и торговли в Горном Алтае во 2-й пол. XIX - 1-й пол. XX в.: историография вопроса / Т. С. Пустогачева [Электронный ресурс] // Вестник Томского государственного университета. - 2010. - № 339. - C. 70-74. - Режим доступа : http://journals. tsu.ru/uploads/import/852/files/339-070.pdf

13. Российский государственный исторический архив (РГИА). - Ф. 560. Оп. 27. - Д. 2 (О сооружении Чуйского тракта, 1884-1902).

14. Старцев А. В. Организация и инфраструктура русской торговли в Монголии во 2-й пол. XIX - нач. XX в. / А. В. Старцев // Россия и Монголия: новый взгляд на историю (дипломатия, экономика, культура). - Иркутск : Изд-во БГУЭП, 2015. - С. 143-180.

15. Старцев А. В. Проектирование и строительство Чуйского тракта во 2-й пол. XIX - нач. XX в. / А. В. Старцев // Хозяйственное освоение Сибири: история, историография, источники. — Томск : Изд-во Том. ун-та, 1991. — С. 177-187. 
16. Старцев А. В. Российско-монгольские торгово-экономические связи в досоветский период и их отражение в отечественной историографии / А. В. Старцев // Концептуальные вопросы российско-монгольских отношений в 1-й пол. XX в. - Улан-Батор; Иркутск : Изд-во БГУ, 2016. - Кн. 7, часть 1. - С. 43-59.

17. Старцев А. В. Строительство Чуйского тракта во 2-й пол. XIX - нач. XX в. [Электронный ресурс] / А. В. Старцев // Ползуновский вестник. - 2004. - № 3. C. 276-282. - Режим доступа : http://elib.altstu.ru/jour-nals/Files/pv2004_03/ pdf/276Starcev.pdf

\section{Информация об авторе}

Канн Сергей Константинович - кандидат исторических наук, старший научный сотрудник, Государственная публичная научно-техническая библиотека СО РАН, 630200, г. Новосибирск, ул. Восход, 15; e-mail: skann@yandex.ru

\section{Author}

Sergey K. Kann - PhD in History, Senior Researcher, State Public Scientific Technological Library of the Siberian Branch of the Russian Academy of Sciences, 15 Voskhod St., 630200, Novosibirsk, Russia; e-mail: skann@yandex.ru 